\title{
Health caregivers' approach towards the rehabilitation of HIV and AIDS persons in uMhlathuze
}

\author{
E.I. Cobham and N.H. Ntombela ${ }^{7}$ \\ Department of Social Work, University of Zululand, Private Bag XI00I, 3886 Kwadlangezwa \\ esygirl@yahoo.com, ecobham@pan.uzulu.ac.za,ntombela@pan.uzulu.ac.za
}

\begin{abstract}
This study examined health caregivers' approach to the rehabilitation of HIV and AIDS persons in uMhlathuze from a social work perspective. The study was a bid to know the efficacy of approaches used in rehabilitating HIV and AIDS persons. In generating data for the study, both qualitative and quantitative research methods, largely through survey by interview and questionnaire and content analysis by review of extant literature was applied. A sample of 50 respondents was purposively drawn from three health centres in the province of KwaZulu-Natal, South Africa, namely Ngwelezana Hospital, Richards Bay Clinic and eNseleni Community Health Centre, by the use of a questionnaire. The interview schedule was administered on 15 respondents in a face-to-face interview. They were also among the 50 respondents that participated in answering the questionnaire: 3 respondents from Richards Bay, 6 from eNseleni CHC and 6 from Ngwelezana Hospital. The study recommends that efforts be made towards the overhauling of equipment, facilities and skilled man-power, in the rehabilitation process.
\end{abstract}

Keywords: Health Caregivers, HIV, AIDS, uMhlathuze, South Africa

\section{Introduction}

The Human Immunodeficiency Virus (HIV) is a retrovirus that belongs to the sub-family lentivirinae, having two distinct types, HIV-I (divided into Group M (10 subtypes), Group O ( 9 subtypes) and Group N (new virus), and HIV-2 (6 (A-F) subtypes), are the aetiologic agents of AIDS. It is a lymphocytotropic and neurotropic virus, which means it can be found in almost all body fluids and organs such as semen, vaginal and cervical secretions and blood. The exchange of these body fluids with an HIV infected individual can lead to transmission of HIV to another person (Baveja \& Rewari, 2005:6).

HIV-I is more easily transmissible than HIV-2 and contributes more heavily to the global pandemic, which poses substantial technical problems for vaccine development (Ramamurthy, 2004:27). HIV infects the body's immune system in particular cells called T lymphocytes ( $T$ cells) which protect against infection and other threats, as it "kills the infected and uninfected cells by several mechanisms and leads to depletion of CD4 cells" (Baveja \& Rewari, 2005:24). With this depletion, opportunistic infections arise such as tuberculosis, meningitis, etc. and "the progression from seroconversion to the development of AIDS" (Baveja \& Rewari, 2005:59).

Acquired Immunodeficiency Syndrome (AIDS) refers to a clinical definition where an individual's immune system has become progressively weak (Ramamurthy, 2004:27). AIDS was first reported in 198I in San Francisco and New York on account of a clustering of diseases Pneumoystis Carinii Pneumonia and Kaposi's Sarcoma, amongst young, otherwise healthy adult homosexuals (Baveja \& Rewari, 2005:16). Invariably, HIV is a precipitating factor that leads to AIDS, which "is a contagious, presently incurable disease that destroys the body's immune system. It is caused by HIV which is transmitted from one person to another primarily during sexual contact or through the sharing of intravenous drug needles and syringes" (Zastrow, 2008:487). The "infection with HIV irrespective of type (HIV-I or HIV-2), subtype and route of infection leads to protracted disease and depletion of CD4 cells in most cases resulting in AIDS" (Baveja \& Rewari, 2005:31). The length of time between initial infection of HIV and the appearance of AIDS symptoms is called the incubation period for the virus (Zastrow, 2008:489).

According to Mattheyse in a TB-HIV fact sheet of the South African Medical Research Council (MRC), (2007), in measuring the extent of the HIV and AIDS epidemic, prevalence and incidence are terms frequently used. Accordingly, prevalent cases have been defined as the people who are infected at a particular time, which include people who have been infected for some time, as well as those who are newly infected. Incident cases are the newly infected people only. In other words, prevalence gives the total number of all cases up till now (less those who have died), whereas incidence tells us how many recent infections have occurred.

The explosive spread of HIV and AIDS is known to have been caused by many factors such as migration; along with urbanisation it is also related to the socio-economic condition of the population where a large segment of the reproductive age group from backward areas migrate to more advanced states in search of employment (Baveja \&

7. Esien Cobham, PhD, is a student in social work at the University of Zululand, South Africa. Ngenisiwe Ntombela, PhD, is acting head of the Department of Social Work, University of Zululand, South Africa. 
Rewari, 2005: II). Violence against women: in settings where violence is regarded as a man's right, women are in a poor position to question their husbands about their extramarital encounters, negotiate condom use or refuse to have sex (Baveja \& Rewari, 2005:10). Better educated people generally have greater access to information than those who are illiterate or uneducated, and they are more likely to make well informed decisions and act accordingly. They generally have better employment and greater access to money and other resources, which can help support healthier life styles (Baveja \& Rewari, 2005:9).

The then President Thabo Mbeki at the opening of the $13^{\text {th }}$ International AIDS Conference in Durban, South Africa, June 2000, suggested that the "cause of AIDS is extreme poverty" (Poku, 2005:3). Although Mbeki's 'temerity' was not acceptable, it does not rule out the fact that poverty has led many into undesirable activities, as insecure livelihoods, and lack of social protection can increase the likelihood of risky behaviour and undermine capacities to cope with the consequences of infection, creating downward spirals in both vulnerabilities of infection and its consequences (Ramamurthy, 2004:29). Gender inequality is a factor which makes women and girls particularly vulnerable because they are often compromised in their ability to negotiate safe sex or to ward-off unwanted sexual attention (Ramamurthy, 2004:28).

Marginalisation is described as the process whereby groups or often entire populations are forced beyond or on the periphery of the social and economic mainstream (White Paper for Social Welfare, Chapter 8, Section 1:62), groups who are made to live on the margins of society exist in every country although they differ from place to place, and what marginalised groups have in common is an increased vulnerability to HIV (Baveja \& Rewari, 2005:10). Mother to child transmission (MTCT) is yet another risk of transmission from an HIV infected pregnant mother to her baby having been reported to be between $2 \mathrm{I}$ and $43 \%$, where various maternal and fetal risk determinants have been reported which play a major role in Mother To Child Transmission of HIV (Baveja \& Rewari, 2005:9), as HIV is a retrovirus transmitted primarily through sexual intercourse, but also through infected blood and from mother to newborn child (Poku, 2005:52).

This is to mention but a few of such factors, with the result being the high rate of persons infected and affected by the HIV and AIDS pandemic, "which respects no territorial boundaries, cast, creed, religion or age" (Baveja \& Rewari, 2005:I). Since the discovery of HIV and AIDS, human existence globally, especially in the third world or developing countries, has been threatened. As earlier mentioned, from 198I when this pandemic was first observed among homosexuals in the United States of America, it posed devastating effects on the socio-economic and man-power development of all nations of the world. "Across the African continent, HIV and AIDS is savagely cutting life expectancy, which is now about twenty less than it would have been without the epidemic, and below forty years in some countries" (Poku, 2005: 5I).

\section{Statement of the problem and purpose of the study}

Clinton Alley (AIDS Guide 2009) asserts that South Africa continues to experience one of the most severe AIDS epidemics in the world. At the beginning of 2008, the number of infected persons living in the country was estimated to be in the region of 5.7 million, with almost 1000 AIDS-related deaths occurring every day. In the absence of an effective medication or vaccine that would decisively deal with this pandemic, and in the face of the changing profile of HIV, where new drugs can now slow disease progression and help people to live longer with an improved quality of life, these same new drugs (ARVs) are often very complicated and have debilitating side effects. "The success with which a person manages to live with the ongoing stress attached to HIV and AIDS impacts directly on his or her quality of life, with growing understanding of HIV and AIDS, according to Catalan et al. (2000) (in Coetzee \& Spangenberg 2002:207); researchers and health care professionals recognise that survival time is not only a question of duration, but also of the quality of life." According to Friedland et al. (1996) (in Coetzee \& Spangenberg 2002:207-208), "quality of life is the patient's appraisal of his or her overall physical, psychological and social functioning, which impacts directly on his or her morale, happiness and satisfaction." In to an article by Adam Currie (2009) titled 'Spirit of Hope' in (Leadership in HIV/ AIDS 2009:47), he asserts that based on a 2007 South African National HIV survey of the nine provinces in South Africa, KwaZulu-Natal still reported the highest percentage of HIV and AIDS. Additionally, the United States Agency for international Development (USAID) has listed KwaZulu-Natal as "the world's highest infected region". The Zululand region is an area where about $35 \%-40 \%$ of the population is HIV positive, with the North Coast area around Empangeni and Richards Bay the most severely affected. It has consistently led HIV prevalence rates, and according to an Amangwe Village fact sheet, "infection rates were increasing more rapidly there than anywhere else in the country".

Against this backdrop, our interest was kindled towards understanding the approaches being employed in rehabilitating the HIV and AIDS persons, in the absence of curative and non-effective preventive medicine, as stated by Campbell in Francis \& Rimensberger (2005:87), "the forces shaping sexual behaviour and sexual health are far more

Inkanyiso, Jnl Hum \& Soc Sci 2010, 2(I) 
complex than individual rational decisions based on simple factual knowledge about health risks, and the availability of medical services".

Based on the high prevalent rate of HIV/AIDS in South Africa, especially the KwaZulu-Natal province, the purpose of this study was to achieve the following objectives with a focus on recent experiences:

- To examine the actual cases of HIV and AIDS attended to by health caregivers in selected health settings, in the uMhlathuze municipality, between the years 2007-2008;

- To identify the various specific approaches employed by health caregivers in health settings, in the uMhlathuze municipality towards the rehabilitation of HIV and AIDS persons they attend to;

- To evaluate the successes and failures of each approach employed by health care givers in the rehabilitation of infected persons within the study area, and

- To stimulate more research on HIV and AIDS, especially in the area of rehabilitation.

\section{Literature review}

Two theoretical frameworks were applied to this study. These were the Rational Choice-based Theoretical Approaches (Gehlert \& Browne 2006:182); made up of the health belief model, the theory of reasoned action, and the theory of planned behavior (Gehlert \& Browne 2006:183-185); the second approach is the Social Network-based Theoretical Approaches (Gehlert \& Browne 2006:185); made up of the social action theory and the behavioural model of health services use (Gehlert \& Browne 2006:187-188). Literature was reviewed on rehabilitation which is seen as being an essential part of a patient's care, as it is here that a person has the opportunity to fulfil his or her potential (Davis 2006:3). To achieve rehabilitation, there is a need to involve a group of professionals all working with the same purpose of meeting the individual's goals, which must involve the individual and their family, as rehabilitation is synonymous with teamwork since it cannot be achieved by one professional group alone (Davis 2006:13). Rehabilitation is not only focused on impairment and disability, but also on the individual's participation in the environment and society (Davis 2006:9), as it is basically client-centered and a link between health and social care.

Therefore, rehabilitation of persons with a physical or mental disability can be defined as restoration to the fullest physical, mental, social, vocational, and economic usefulness of which they are capable. To achieve this, a wide range of professionals provide rehabilitation services, such as physicians (medical doctors), nurses, clinical psychologists, physical therapists, psychiatrists, occupational therapists, recreational therapists, vocational counselors, speech therapists, hearing therapists, industrial arts teachers, social workers, special education teachers, and prosthetists. Most of these therapists focus on the physical functioning of the clients, whereas social workers focus primarily on their social functioning (Zastrow 2008:523-524).

A report by WHO (2005) states that the number of people with disabilities is increasing. Classes of such disabilities are from war injuries, landmines, HIV and AIDS, malnutrition, chronic diseases, substance abuse, accidents and environmental damage, population growth, medical advances that preserve and prolong life, are contributors to the increase in disability. These trends create an overwhelming demand for health and rehabilitation services. The report went further to state that to ensure equal opportunities and promotion of human rights for people with disabilities, especially the poor, WHO would adopt and implement three of the rules of the United Nations' Standard Rules on the Equalisation of Opportunities for Persons with Disabilities, issued as guidelines for health, education, work and social participation. These are:

Rule 2. Medical care - States should ensure the provision of effective medical care to persons with disabilities.

Rule 3. Rehabilitation - States should ensure the provision of rehabilitation services to persons with disabilities in order for them to reach and sustain their optimum level of independence and functioning.

Rule 4. Support services - States should ensure the development and supply of support services, including assistive devices for persons with disabilities, to assist them to increase their level of independence in their daily living and to exercise their rights (WHO 2005).

From this report, persons with HIV and AIDS have been identified amongst others by WHO as beneficiaries of rehabilitation services because they face challenges that demand a holistic approach towards their treatment, as complications resulting from HIV and AIDS radically alter the physiological and psychological well-being of HIV-infected persons. Treatment with highly active anti-retroviral therapy (HAART) allows HIV-infected persons to live longer, healthier, and more productive lives than was possible at the beginning of the HIV and AIDS pandemic. However, these life-extending antiretroviral medications often have side effects that adversely affect the quality of life. Medical researchers, such as the South African AIDS Vaccine Initiative (SAAVI) a lead programme of the Medical Research Council (MRC), are continually seeking more effective methods to treat infected persons; a vaccine that effectively prevents HIV infection is the ultimate goal (Dudgeon et al. 2004:8I), although "according to medical establishment, there is currently neither a cure nor a vaccine to neutralise HIV" (Cloete 2007:56). 
In a bid for the way forward, on the 13-14 May 2009, at the Richards Bay Hotel in Richards Bay, South Africa, a conference was organised by the University of Zululand, with the theme: The HIV and AIDS in Higher Education, $21^{\text {st }}$ Century Challenges, with sub-themes: Building a supportive environment; HIV and AIDS Culture and Traditional Medicine; HIV and AIDS and gender; Media as a communication Strategy (Leadership in HIV \& AIDS 2009:47). This conference was in line with the purposes of the National Strategic Plan (NSP) 2007 - 201I, one of which is the Operational Plan for Comprehensive HIV and AIDS Care, Management and Treatment for South Africa in providing comprehensive care and treatment for people living with HIV and AIDS as well as to facilitate the strengthening of the national health system, as well as other agencies working on HIV and AIDS in South Africa, within and outside the government (HIV \& AIDS Strategic Plan 2007-20II:53). The goals of the National Strategic Plan 2007 - 2011 are summarised as:

Primary Goals

- Reduce the number of new infections by $50 \%$

- Reduce the impact of HIV and AIDS in individuals, families, communities and societies, by expanding access to appropriate treatment, care and support to $80 \%$ of all people diagnosed with HIV.

The interventions that are needed to reach the aims of the National Strategic Plan are structured according to the following four priority areas:

- Prevention;

- Treatment, care and support;

- Human and legal rights: and

- Monitoring, research and surveillance (HIV \& AIDS Strategic Plan 2007-20 I I:56).

The challenge posed by the HIV and AIDS epidemic and by the resurgence of tuberculosis and other medical conditions is how to further shape health care systems to respond to individual and local needs, which is not simply a matter of reacting to conditions but taking advantage of new or emerging therapies. In the context of HIV and AIDS, health systems are expected to develop additional services to HIV and AIDS, some of which are already in place, such as voluntary counselling and testing services (Poku 2005:128), as well as home based care. Although, as posited by Kaleeba et al. in Poku (2005:129), "home or community care is not about 'decongestion of hospital beds', but about the provision of a comprehensive range of medical, nursing, counselling, spiritual, as well as nutritional care, which must exist from hospital to home, i.e. continuum of care."

Based on this, the social disability grant has been of much help to ease most of the burdens of infected persons and their family, as it has helped meet certain basic needs. However, "the social grants given to child families are also not enough, they do not cover all the costs like electricity, water and school fees. The grants only take the edge off hunger. Poverty exacerbates the pandemic. Families often demand help from a stricken member because the member is their 'ATM'. If a patient's viral load improves, relatives force that person to stop taking antiretroviral because they fear that the grant will be taken away" (Real 2008:29). In this vein, the rehabilitation of HIV and AIDS infected persons is considered to be physical (physiotherapy, occupational therapy, speech therapy, audiology, complementary or alternative therapies, etc.), psychosocial (psychotherapy, social supports, etc.) and vocational rehabilitation (Canadian Working Group 2009 \& Care for People 2008).

Relevance of social work in health care

Social Work in health care settings is practised in collaboration with medicine and also with public health programmes. It is the application of Social Work knowledge, skills, attitudes, and values to health care. Social Work addresses itself to illness brought about by or related to social and environmental stresses that result in failures in social functioning and social relationships. It intervenes with medicine and related professions in the study, diagnosis, and treatment of illness at the point where social, psychological, and environmental forces impinge on role effectiveness (Farley, Smith, \& Boyle 2006:173).

Medical Social Work is shaped and guided by the attitude, beliefs, knowledge, and acceptable ways of doing things by professionals serving in health care institutions and by the philosophy and practice of modern medicine. It requires knowledge of illness and of the psychological and social impact of disease on the individual, the family, and the family interrelationships; it calls for the application adaptation of Social Work concepts, principles, and ideas to the special needs of hospital and clinic clientele (Farley, Smith, \& Boyle 2006: 176). Social Workers in health care services use the problemsolving method in assisting individuals, groups, and communities in solving personal and family health problems. Social Work is involved at various levels of prevention:

Primary - health education, encouraging immunisations, good mental health practice in families, prenatal and postnatal care;

Secondary - early screening programmes for detection of disease, checkups, encouraging treatment;

Inkanyiso, Jnl Hum \& Soc Sci 2010, 2(I) 
Tertiary or rehabilitation - preventing further deterioration of a disease or problem (Farley, Smith, \& Boyle 2006: 175).

The functions of Social Work in the hospital ,according to Farley, Smith, \& Boyle (2006: $178-179)$, include:

I. Assess the patient's psychological and environmental strengths and weaknesses.

2. Collaborate with the team in the delivery of services to assure the maximum utilisation of the skill and knowledge of each team member.

3. Assist the family to cooperate with treatment and to support the patient's utilisation of medical services.

4. Identify with a cadre of other professionals to improve the services of the hospital by an interdisciplinary sharing of knowledge.

5. Serve as a broker of community services, thus providing linkages of patient need with appropriate resources.

6. Participate in the policy-making process.

7. Engage in research to assure a broadening of the knowledge base for successful practice

Roles of social work in rehabilitation

Rehabilitation for people with a physical or mental disability has been defined as restoration to the fullest physical, mental, social, vocational and economic usefulness of which they are capable. Services rendered are on vocational training, vocational counselling, psychological adjustment, medical and physical restoration, and job placement, although these are administered based on client's needs for such services (Zastrow 2008:523).

Social work in the medical or health setting is basically practiced in the hospital. With a wide variety of problems and situations encountered, social work in the health field is dynamic and requires continued study, as the dramatic expansion of new therapy approaches for medical conditions poses a challenge (Zastrow 2008:503). Social workers provide not only direct casework with patients and their families, but also group work with certain patients, consultation, and training of other professionals. They are also involved in planning and policy development within the hospital and with various health agencies (Zastrow 2008:50I). One of the emerging fields of practice for medical social work is combating AIDS. Social workers are getting involved in advocating for programmes that would assist in reducing discrimination against persons with HIV and AIDS, they are also involved on counselling and in providing services in hospitals, residential treatment centers, nursing homes, and hospices to those that are positive. Social workers also serve as case managers for many people with AIDS. The case manager works with the affected persons, their loved ones, providers of care, and payers of health care expenses to make certain that pressing medical, financial, social, and other needs are met and to ensure that the most cost-effective care possible is provided.

In serving persons affected, the trend is to have more and more of the medical care delivered outside the hospital or nursing home, often at the person's home or in an outpatient clinic (Zastrow 2008:504). As cited by Kaleeba et al., in Poku (2005:129), "home or community care is not about "decongestion of hospital beds" but about the provision of a comprehensive range of medical, nursing, counselling, spiritual, as well as nutritional care which must exist from hospital to home, i.e. continuum of care'. Invariably, one of the most difficult tasks of doctors, nurses, social workers, and other allied professionals in the health field is to help a terminally ill patient deal with dying (Zastrow 2008:505). And to achieve this, social workers generally function as members of a team, and they need to learn to work with those in charge.

Medical treatment teams are increasingly dependent on social workers to attend to socio-psychological factors that are either contributing causes of illnesses or side effects of a medical condition that must be dealt with to facilitate recovery. As a member of a medical team, social workers have an important role in diagnosing and treating medical conditions. Social work in the health setting needs skills and knowledge about how to counsel people with a wide variety of medical conditions, which requires a high level of emotional maturity, a well-thought-out identity, and a high level of competency in counselling (Zastrow 2008:508). In rehabilitation services, social work services are various, such as counselling clients, counselling families, taking social histories, serving as case managers, serving as liaison between the family and the agency, being a broker, as well as doing discharge planning (Zastrow 2008:523-524).

\section{Research design}

Both qualitative and quantitative research design was used for this study, its aim was to ascertain the link that exists between the approaches employed by health care givers, the target of the research which is on rehabilitation and the incessant increase on the prevalence rate of HIV and AIDS infected persons. In the first instance, survey method was employed through the use of questionnaires and personal interview to purposely selected health workers. Our target population for the study comprised of health caregivers involved in the rehabilitation of HIV and AIDS persons in three selected health centres within the uMhlathuze municipality, namely: The Richards Bay Clinic, eNseleni Community Health Centre and the Ngwelezana Hospital. 
As far as sampling is concerned, we made use of the non-probability sampling technique through purposive (judgmental) sampling. Only health care workers directly involved in the rehabilitation services of HIV and AIDS infected persons were considered qualified for the study. Firstly, questionnaires were distributed to purposefully selected 50 respondents. These include: II from Richards Bay Clinic, 16 from eNseleni CHC and 23 from Ngwelezana Hospital. Among the 50 respondents who answered the questionnaires, 16 key informants were also interviewed from each profession available, 4 from Richards Bay Clinic, 5 from eNseleni CHC and 6 from Ngwelezana Hospital.

Ethical issues are very important in research. We took into cognisance the rights and privacy of participants, as well as their consented participation in the study was sought and granted. We made certain to observe all ethical considerations and conduct attached to a study considered to be of a very high sensitive nature after obtaining permission to conduct study from the concerned ethical bodies. Quantitative data were analysed by the use of closed items, which made use of tables and graphs. While for the qualitative data, open-ended items were analysed using the descriptive analysis method.

\section{Results}

The results are discussed under items 5.I to 5.4, Table I and Figures I and 2 as represented below

5.1 Actual cases of HIV and AIDS attended to by health caregivers in selected health settings, within the uMhlathuze municipality.

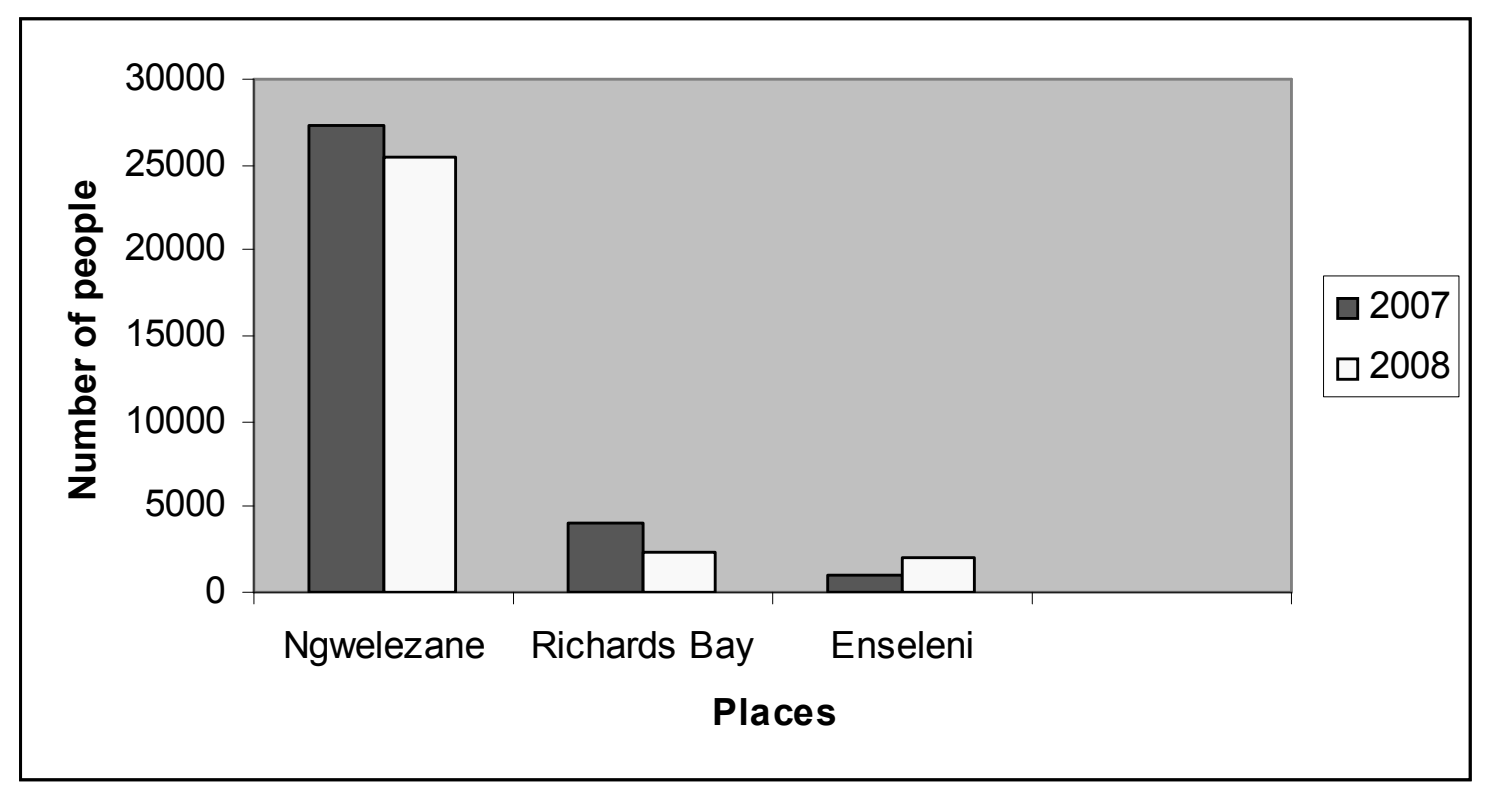

Figure 1 Number of cases attended to in 2007-2008

From the study conducted, health caregivers interviewed were able to supply us with the total number of infected cases attended to between the years 2007 and 2008. From Richards Bay Clinic, the total number of infected persons attended to were 4,400 in 2007 and 2,299 in 2008, from eNseleni Community Health Centre the total numbers were I,065 for 2007 and 2,05 I for 2008. While for Ngwelezana Hospital the total numbers of infected persons attended to were 27,277 for 2007 and 25,506 for 2008. Although there is a drop in the prevalent rate figure between 2007 and 2008 for Richards Bay Clinic and Ngwelezana Hospital, All three health centres agree that there is still an increase rate in the HIV/AIDS prevalence because more infected persons do not continue with their treatment when placed on referrals, or discontinue treatment so that when their CD4 count drops, they can still benefit from the social grant. In line with this, it was noted that the prevalence rate was still on the increase.

From this, we were able to find out that health workers in these health settings sacrificed a lot to give their humanitarian services, as Richards Bay Clinic is basically made up of nurses and lay-counsellors only, there are no medical doctors, social workers, dieticians, dentists, physiotherapists and the rest, and so they do have a huge challenge in service delivery. For example, when referrals are made for a patient, the patient most often does opt out of treatment because of the change in treatment environment, this is mostly due to the fear of not wanting their status to be exposed, which brings about a high standard of confidentiality to be upheld. From eNseleni CHC, the health team is fairly represented but Inkanyiso, Jnl Hum \& Soc Sci 2010, 2(I) 
with only one social worker to attend to all patients, whether HIV and AIDS infected or not. There are no dieticians, speech therapist, physiotherapists, occupational therapists, and the rest. Ngwelezana Hospital is a much bigger hospital with basically all the health professionals, who are well represented to provide rehabilitative treatment to infected persons. Within the hospital, there is a special unit by the name Thembalethu Clinic where HIV and AIDS adults are treated.

Also, from the three health centres, despite the huge number of infected persons being attended to, they face a similar challenge of a shortage of skilled persons, as well as a lack of insufficient space to contain the number of infected persons they have to deal with especially on their clinic days. And so, even the issue of complete confidentiality cannot be adhered to, as infected persons can easily be identified on the long queues that are formed on each clinic days.

5.2 Specific approaches employed by health caregivers in health settings in the uMhlathuze municipality towards the rehabilitation of HIV and AIDS persons they attend to

From information gathered, we were able to identify the various approaches employed in the holistic treatment of HIV and AIDS persons, as well as the involvement of significant others, such as the family, the community, the government and other stakeholders with keen interest on the HIV and AIDS issues. The various approaches mentioned by respondents were the drug therapy, the social group support, family involvement, nutritional support, vocational rehabilitation, physiotherapy, health education, psychotherapy, social disability grant, referrals, occupational therapy, speech therapy, community involvement, and counselling.

The findings of the study revealed that although health caregivers from Richards Bay Clinic were basically made up of professional nurses and lay counsellors, as well as being short staffed, they are faring very well with such approaches as counselling, drug therapy and health education. They also check the viral load of infected persons, and where there is a challenge, referrals are done. Findings from eNseleni $\mathrm{CHC}$ revealed that although health caregivers were made up of medical doctors, nurses, a social worker, and pharmacists, they were still very short staffed, even though they employed the peer support group and family/community support which have fared very well in boosting the morale of infected persons. Basically, the approaches employed here are the psycho-social, social/peer group support, nutritional support, vocational rehabilitation, counseling, health education, community involvement and the social disability grant, which is described as being episodic because it has to be reviewed after six months just as the HIV and AIDS is episodic.

Table I Presentation of approaches identified by health caregivers in the rehabilitation of HIV and AIDS persons

\begin{tabular}{|l|l|}
\hline Responses & Number of Respondents \\
\hline Pharmacological approach (Drug Therapy) & 25 \\
\hline Social group support & 26 \\
\hline Nutritional support & 15 \\
\hline Family therapy & 17 \\
\hline Vocational rehabilitation & 5 \\
\hline Physical rehabilitation & 8 \\
\hline Health education & 17 \\
\hline Psycho social rehabilitation & 5 \\
\hline Social disability grant & 15 \\
\hline Referral & 10 \\
\hline Occupational therapy & 2 \\
\hline Speech therapy & 4 \\
\hline Community involvement & 2 \\
\hline Counselling & 4 \\
\hline
\end{tabular}

While findings from Ngwelezana Hospital revealed that although health caregivers were made up of medical doctors, nurses, social workers, psychologists, psychiatrists, physiotherapists, occupational therapists, speech therapists, lay counsellors, and one dietician, others such as audiologists, dentists, pharmacists and infection control were also identified by the researcher as being involved in the rehabilitation of HIV and AIDS persons, even though they were not a part of the study, yet this establishment is short staffed considering that there is only one dietician in the hospital, one full time 
speech therapist and two part time. Even social workers are but a hand full. With the number of infected persons to be treated, most times the bulk of the work rests especially on the nurses, the lay counsellors and the social workers.

In using the speech therapy, language and feeding are dealt with in the sense that the muscle might get weak and with this weakness, the infected person becomes disabled which leads to speech and feeding disability. Physical rehabilitation is another relevant approach, as it improves the patient's movement to function properly, this is mostly utilised at the chronic stage. Nutritional support is also very relevant, as its role is basically to choose the right type of food or nutrition for the infected. Based on much intake of several drugs, i.e. the antiretroviral drugs, infected persons most often suffer depression, dementia, anxiety, et cetera, in reaction to this intake. Psychiatrists, psychologists, social workers, et cetera, play a major role in treatment here, and also in bridging the gap about reintegrating infected persons back into the society.

5.3 The successes and failures of the approaches employed by health caregivers in the rehabilitation of infected persons within the study area

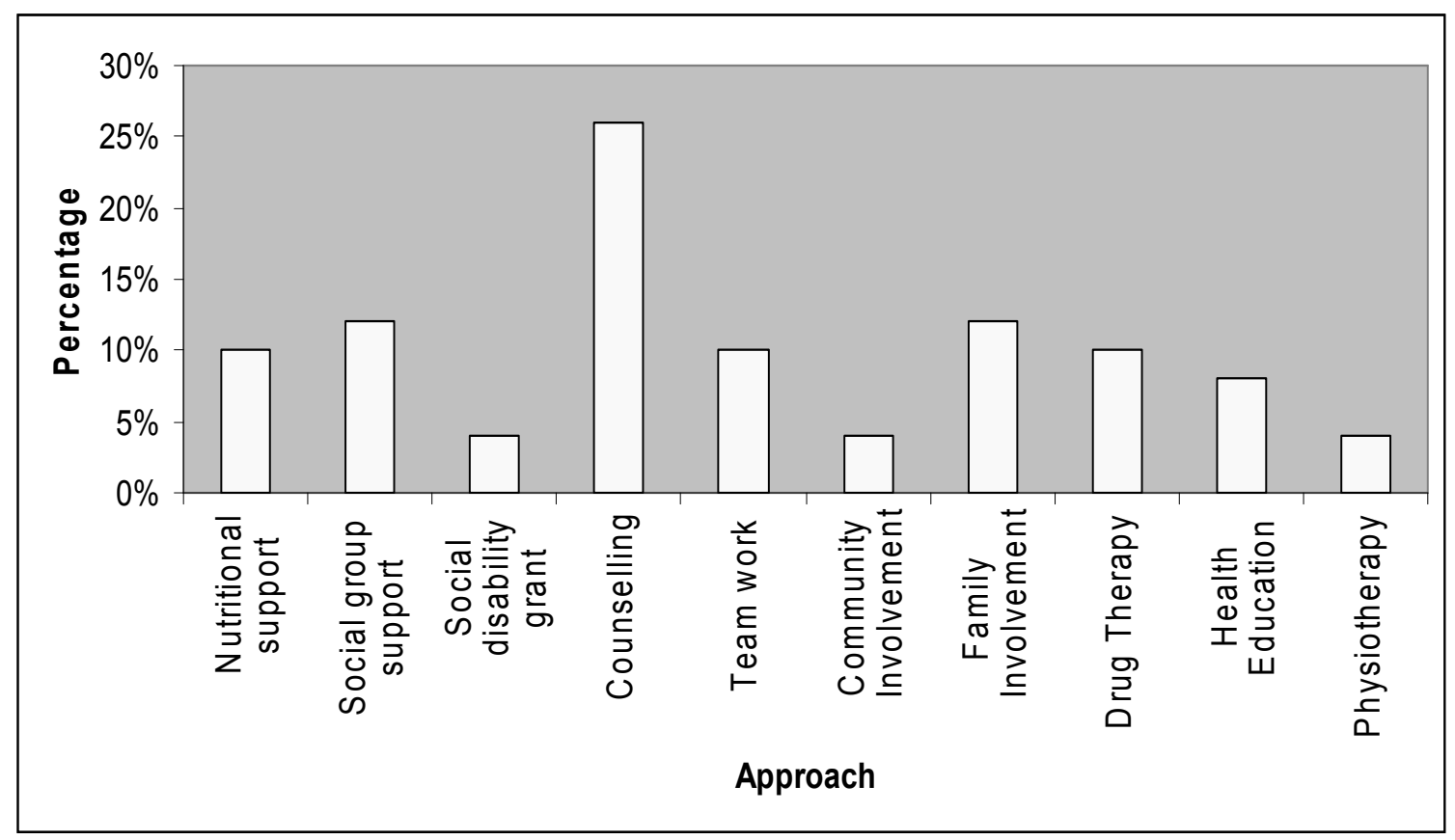

Figure 2 Presentation of approaches by percentage

From the study, $26 \%$ of respondents (13) ranked counselling to be the most effective and efficient approach utilised by health care workers, followed by the social group support which was indicated by $12 \%$ of the respondents (6), same as the family involvement which also had $12 \%$ respondents (6). Nutritional support, drug therapy and team work, each had $10 \%$ of respondents (5), health education was listed by $8 \%$ of respondents (4), while social disability grant, community involvement and physiotherapy each had $4 \%$ of respondents (2).

For successes, counselling (one-on-one) is very effective for patients, although time consuming. Social disability grant although effective as it offers financial relief and support to the very poor, is faulted as infected persons are prone to stop treatment when their CD4 count goes above 200 so as to continue benefiting from the disability grant which is episodic in nature, just as the HIV and AIDS disease. Family and community involvement were viewed to be very therapeutic from all three health centres and is much encouraged, though much is still expected from these approaches. Nutritional support is also effective as it provides food parcels for patients and relatives. Drug therapy although very effective, relies on other approaches for its efficacy. Physiotherapy was also listed as one of the effective approaches being utilized, although its usage depended on the patient's need or challenge at a particular time in the course of treatment. Health education and social group support plays a vital part in treatment, although the social group support has its pit-fall, as some patients refuse participation. Evidently, team work comes into play and has been viewed to be effective, but its pit-fall is the refusal of some patients to be referred, as well as insufficient professional health workers.

Inkanyiso, Jnl Hum \& Soc Sci 2010, 2(I) 


\subsection{Further research on HIV and AIDS in the area of rehabilitation}

From the interview conducted, each respondent was of the opinion that much still needed to be done on the HIV and AIDS issue, especially in the area of rehabilitation.

From the Richards Bay Clinic, the general notion was that as KZN still has the highest rate of prevalence, much still needs to be done, in consideration to culture and ignorance, despite information from the media and the general awareness. From Ngwelezana Hospital, respondents suggested that more researching needs to be done in the area of rehabilitating HIV and AIDS persons, due to the escalating increase in the number of persons infected; as poverty is a problem and education do not change people's attitude and behaviour as the most common means of getting infected is through heterosexual relationships. From eNseleni $\mathrm{CHC}$, respondents agreed that researching on approaches utilised by health caregivers towards the rehabilitation of HIV and AIDS persons, was very necessary, as the prevalence rate is alarmingly on the increase, either due to new infection or more awareness that would require prompt testing.

\section{Conclusion and recommendations}

According to Steiner et al. in Davis (2006: ix), rehabilitation is defined as a complex process which depends on interprofessional working and should be focused on the individual's goals. HIV and AIDS is a chronic ailment that is described as being episodic as it fluctuates between a state of wellness and illness, and "for intervention to be effective, the consideration of the cultural explorations and people's perceptions of illness, disease and well-being are as important as knowledge of biomedical facts" (Williams et al. 2000:131). Based on this, the Rational Choice-based and Social Network-based Theoretical Approaches were applied to this study, as presented in chapter two, towards the holistic treatment of HIV and AIDS persons in the society, as these approaches embrace every aspect of health care in treatment.

According to a World Health Organisation report (2000), governments have been urged to recognise that they are ultimately responsible for a country's health system though care may be provided by a combination of private, non-profit and public agencies, "governments must be the prime mover." Likewise, states are to be responsible for anticipating the needs associated with home-based, long-term care, which extend beyond the provision of health care services, and for ensuring that resources are available and are distributed efficiently and equitably (WHO 2002:2). This can only "be achieved in situations where all the care methodologies are delivered appropriately in adequate quality and quantity" (Baveja \& Rewari 2004:253). This is not just providing care, but the dissemination of expertise or professional skills, starting from the health settings to the home, which will go along way to end child-headed families and the deprivation of family members not attaining their goals in life because of giving care to a sick family member, et cetera, as well as meeting with the millennium development goal for 2015 which is to reduce the rate by $50 \%$ (HIV \& AIDS National Strategic Plan 2007-201 I:56).

In conclusion, "any real society is a caregiving and care-receiving society, and must, therefore, discover ways of coping with these facts of human neediness and dependency that are compatible with the self-respect of the recipients and do not exploit the caregivers" (WHO 2002:44).

Based on the research findings as obtained from the study, recommendations were suggested such as; Continuous support from the government, by formulating and implementing policies that would effectively bridge the gap between strategies on achieving set goals and the achievement of such set goals; a community based rehabilitation unit or centre with outreach to be set up; rehabilitation teams to visit primary health clinics, homes, on daily basis to offer services; there is a crucial need for more qualified professional personnel to be employed in health centres, as well as a crucial need for the employment of more health social workers in the public health service; implementation of expertise to the various specialised fields is required, as well as in-training for health professionals to meet up with the ever changing and innovative trends of therapies towards the rehabilitation of HIV and AIDS persons; funding for community based rehabilitation is essential to the growth and development of such communities, improvement on community or home based rehabilitation is very necessary as the provision of continuous physical and psychological care and support from the community and government agencies serve to extend fruitful life as much as possible (Baveja \& Rewari 2004:253); spiritual involvement and recreational approach is also of very high relevance; expansion of multidisciplinary team to involve complementary therapies; establishment of more male HIV and AIDS Care Programmes in all private and public health centres; there is requirement for adequate space in health centres for much more effective service delivery and the provision of incentives to health workers; improvement on home care education is very necessary, as professional expertise and home based care are of vital importance; there is further need for the provision and proper maintenance of hospital facilities and man-power, as well as the availability of such services, where and when needed. 


\section{References}

AIDS Guide 2009. Official Guide Book. Global players recognise that prevention is better than cure. University of Zululand. Uhuru Communications cc. Claremont.

Baveja, U.K. \& Rewari, B.B. (2004). Diagnosis and Management of HIV/AIDS, A_Clinician's Perspective. New Delhi: B.I. Publications Pvt. Ltd.

Canadian Working Group on HIV and Rehabilitation. (2009). http://www.hivandrehab.ca/EN/information/people_HIV/types_rehab

Care for People Living with HIVIAIDS. (Updated February 2008). File://C:/Documents\%20and\%20Settings/PostGrads/Desktop/ rehab.

City of uMhlathuze. The Dawn of a New Era. Annual Review 2007/08.

Cloete, M. (2007). HIV/AIDS and Modernity in Africa: A Philosophical Perspective. Acta Academica, 2008,40 (2): 53 - 81.

Coetzee, M. \& Spangenberg, J. (2002). Coping Styles and Quality of Life in People with HIV/AIDS: A Review. Acta Academica, 2003, 35 (3): 205-222.

Davis, S. (2006). Rehabilitation the Use of Theories and Models in Practice. Edinburgh: Churchill Livingstone Elsevier Limited.

Department of Welfare. (1997). White Paper for Social Welfare: Principles, Guidelines, Recommendations, Proposed Policies and Programmes for Developmental Social Welfare in South Africa. Department of Welfare Population and Development.

Dudgeon, W.D., Phillips, K.D., Bopp, C.M., \& Hand, G.A. (2004). Review: Philosophic and Psychological Effects of Exercise Interventions in HIV Disease. AIDS PATIENT CARE and STDs; Volume 18, Number 2.

Farley, O.W., Smith, L.L., Boyle, S.W. (2006). Introduction to Social Work. (I0 ${ }^{\text {th }}$ edition). Boston: Pearson Education, Inc.

Fox, J. (2002). Nkosi's Story. Claremont: The Life Story Project \& Spearhead.

Francis, D. \& Rimensberger, N. (2005). Selling HIV/AIDS Prevention: A Case of Mixed Messages. Acta Academica. (2005) 37 (3): $86-105$.

Gehlert, S. \& Browne, T.A. (2006). Handbook of Health Social Work. New Jersey: John Wiley \& Sons, Inc.

HIV and AIDS and STI Strategic Plan for South Africa, 2007 - 20I I. March 2007 (Draft 9).

Leadership in HIV \& AIDS. Spirit of Hope. Issue 26, June 2009. Rondebosch.

Maile, S. Managing the Disclosure of School Learner's HIV Status. Acta Academica. (2003) 35 (3): 185 - 204.

Mattheyse, M. (2007). Prevalence Versus Incidence of HIV - What do they tell us? South African Medical Research Council. http:// www.mrc.ac.za/public/facts//.htm

Parkhurst, J.O and Lush, L. The Political Environment of HIV: Lessons from a Comparison of Uganda and South Africa. Social Science and Medicine 59 (2004).

Poku, N.K. (2005). AIDS in Africa, How the Poor are Dying. Cambridge: Polity Press.

Ramamurthy, V. (2004). Strategic Approaches to HIV and AIDS Prevention and Control. Delhi: Authorspress.

Real Magazine. June 2008. Melrose Arch.

South African AIDS Vaccine Initiative (SAAVI). SOUTH African Developed HIV Vaccines Begin Testing in the US and SA. News Release; 28 November, 2008. http://www.saavi.org.za

Verma, Col. A. K., Singh, Brig. Z., Bishnoi, Col. M.S. Social Rehabilitation of HIV/AIDS Orphans. Mjafi. (2006) Volume 62, Number 4: 396 - 397.

Williams, B.G., Gilgen, D., Campbell, C.M., Taljaard, D., and Macphail, C. (CSIR, Johannesburg, 2000). The Natural History of HIV/AIDS in South Africa: A Biomedical and Social Survey in Carletonville. Council for Scientific and Industrial Research. Auckland Park 2006.

World Health Organization (2005). Disability, Including Prevention, Management and Rehabilitation. $58^{\text {th }}$ World Health Assembly, Provisional Agenda Item 13.13. A58/I7.

World Health Organization (2002). Ethical Choices in Long - term Care: What Does Justice Require? WHO Library Cataloguing - in - Publication Data. http://www.who.int/ncd/long_term_care/index.htm

Zastrow, C. (2008). Introduction to Social Work and Social Welfare: Empowering People (9 $9^{\text {th }}$ edition). Belmont: Thomson Brooks. 